Article

\title{
Evaluation of the In Vitro Wound-Healing Activity and Phytochemical Characterization of Propolis and Honey
}

\author{
Alexandra M. Afonso ${ }^{1}$, Joana Gonçalves ${ }^{1,2,+}$, Ângelo Luís ${ }^{1,2, *,+} \mathbb{( D}$, Eugenia Gallardo ${ }^{1,2} \mathbb{D}$ and \\ Ana Paula Duarte 1,2,*(D) \\ 1 Centro de Investigação em Ciências da Saúde (CICS-UBI), Universidade da Beira Interior, Avenida Infante D. \\ Henrique, 6200-506 Covilhã, Portugal; alexandrafonso9@gmail.com (A.M.A.); \\ janitagoncalves@hotmail.com (J.G.); egallardo@fcsaude.ubi.pt (E.G.) \\ 2 Laboratório de Fármaco-Toxicologia, UBIMedical, Universidade da Beira Interior, Estrada Municipal 506, \\ 6200-284 Covilhã, Portugal \\ * Correspondence: angelo.luis@ubi.pt (Â.L.); apcd@ubi.pt (A.P.D.); Tel.: +351-275-329-002 (Â.L.); \\ +351-275-329-099 (A.P.D.) \\ + These authors contributed equally to the work.
}

Received: 17 February 2020; Accepted: 4 March 2020; Published: 7 March 2020

\begin{abstract}
Honey and propolis are natural substances produced by Apis mellifera that contain flavonoids, phenolic acids, and several other phytochemicals. The aim of this study was to phytochemically characterize three different types of honey and propolis, both separately and mixed, and to evaluate their wound-healing activity. Total phenolic compounds and flavonoids were determined using the Folin-Ciocalteu's and aluminum chloride colorimetric methods, respectively. The antioxidant activity was evaluated by both the DPPH free radical scavenging assay and $\beta$-carotene bleaching test, and the anti-inflammatory activity was determined by a protein denaturation method. To evaluate the wound-healing activity of the samples, NHDF cells were subjected to a wound scratch assay. The obtained results showed that dark-brown honey presents a higher concentration of phenolic compounds and flavonoids, as well as higher antioxidant and anti-inflammatory activities. Propolis samples had the highest concentrations in bioactive compounds. Examining the microscopic images, it was possible to verify that the samples promote cell migration, demonstrating the wound-healing potential of honey and propolis.
\end{abstract}

Keywords: honey; propolis; phenolic compounds; antioxidant; wound-healing activity; NHDF cells

\section{Introduction}

Honey is a natural substance produced by the western honeybee (Apis mellifera) from nectar and exudates of flowers and trees. Honey contains flavonoids, phenolic compounds, and numerous sugars in its composition, mainly glucose and fructose. It also contains small amounts of minerals, vitamins, proteins, and enzymes [1-5].

Propolis is a resinous substance produced by the same species of bees, being composed of wax, resinous secretions from plants, tree buds, pollen, and salivary enzymes. Propolis contains essential oils and organic compounds such as phenolic acids and flavonoids [4,6-8]. Similarly to honey, propolis also contains several minerals, vitamins, and enzymes [9]. This substance is used to protect the beehive, acting as a natural sealant, antiseptic, and embalming agent $[1,4,6-8,10]$.

The color and flavor of both honey and propolis vary according to the plant species used in their production, health state of the bees, season, and the environmental conditions to which the beehive is exposed [2-5]. The color of the honey can vary from deep brown to yellow, and propolis 
can be found in variations of green, red, or brown $[6,7,11]$. Differences in their composition result in different biological activities $[1,4,7,12]$. Honey and propolis have been used in traditional medicine for thousands of years mainly in burns and infected lesions [4,10]. Propolis was used primarily as an oral antiseptic and in dermal lesions. In ancient Egypt, propolis was also employed in mummification [6].

The main mechanism of action of honey derives from its antioxidant and anti-inflammatory activities $[1,2,10]$. The antioxidant potential of honey is due to the presence of phenolic compounds, namely gallic acid and flavonoids, that promote the free radical scavenging [2,10]. Its anti-inflammatory activity is associated with the ability to increase cellular proliferation, autolytic debridement, and to stimulate the immune system, reducing edema and pain [10]. Propolis has a higher content in flavonoids and phenolic acids than honey, which suggests that propolis should have a higher antioxidant and anti-inflammatory activities [1,7].

Currently, an increasing interest in mixing propolis with honeys was verified, as products including propolis are already available on the market. The commercial achievement of these products is dependent of the level of acceptance and expectations of the consumers [1]. However, the potential benefits of adding propolis to honeys is still to be scientifically validated.

Wounds are responsible for the consumption of large amounts of healthcare resources to ameliorate the quality of life of patients, and so they represent a considerable health challenge. Several scientific experiments have been performed to find novel compounds that possess wound-healing properties, particularly from natural sources [13]. Honey was employed for the repair of battle wounds in both World War I and in modern history. The healing activity of honey in infected wounds was initially described in Europe and USA in mid-20 th century [10]. Moreover, evidences suggest that propolis has therapeutic activity, through quantitative and qualitative analyses of collagen types I and III expression and degradation in wounds matrix, which suggests the favorable biochemical environment supporting re-epithelization of propolis [11].

The first aim of this study was to phytochemically characterize different samples of honey and propolis together with mixtures of propolis extracts with honey in different concentrations, determining the contents in total phenolic compounds and flavonoids, as well as evaluating the antioxidant and anti-inflammatory activities. The second purpose of this work was to evaluate the in vitro wound-healing activity of the samples using normal human dermal fibroblasts (NHDF) by means of the scratch assay.

\section{Materials and Methods}

\subsection{Honey and Propolis Samples}

Honey and propolis samples were collected from a Langstroth beehive in a mountainous forest in the north central Portugal, specifically in the region of Sabugal (Guarda) during September 2018 (GPS coordinates: $40^{\circ} 23^{\prime} 33.5^{\prime \prime} \mathrm{N} 7^{\circ} 03^{\prime} 45.4^{\prime \prime} \mathrm{W}$ ).

Three different samples of honey and propolis were collected from the same beehive to maintain consistent the conditions of production. Each honey sample was collected from a different box inside the hive and was then filtered individually until there was no visible debris or particles. Propolis samples were scraped from the boxes and frames of the hive and then separated according to the box from which they were collected. All samples were stored individually in an appropriate sterilized container.

Dark-brown honey was considered as Honey 1 (H1), red honey was labeled as Honey 2 (H2), and light-yellow honey was identified as Honey 3 (H3). Propolis samples were named according to the box from which the honey samples were collected as Propolis 1 (P1), Propolis 2 (P2), and Propolis 3 (P3).

\subsection{Propolis Extracts}

The samples of propolis were grounded individually in a marble mortar at room temperature. To start the extraction process, $100 \mathrm{~mL}$ of ethanol (Scharlab, Spain) were added to $14 \mathrm{~g}$ of each pulverized propolis sample. The mixtures were left for $48 \mathrm{~h}$ under magnetic stirring at room temperature and in 
the absence of light. After $48 \mathrm{~h}$, the mixtures were filtered and transferred to round bottom flasks to evaporate the ethanol using a rotary evaporation system at $45^{\circ} \mathrm{C}$. To ensure the complete evaporation, the round bottom flasks were kept in a vacuum oven for $24 \mathrm{~h}$ at $35^{\circ} \mathrm{C}$.

The propolis extracts were labelled as Propolis Extract 1 (PE1), Propolis Extract 2 (PE2), and Propolis Extract 3 (PE3) and were frozen at $-20^{\circ} \mathrm{C}$ until they were used.

\subsection{Mixtures of Honey with Propolis}

Each propolis extract was added in a concentration of $0.3 \%(\mathrm{w} / \mathrm{w})$ and $0.5 \%(\mathrm{w} / \mathrm{w})$ to the Honey 1 (the one that presented the best results), according to the previously published work dealing with the evaluation of the bioactive properties of honey with propolis [1]. The mixtures were prepared by weighting the corresponding amounts of honey and propolis and mixing them to complete $100 \mathrm{~g}$ of each mixture. To guarantee the complete homogenization, all mixtures were subjected to mechanical stirring, after which they were stored at $-20^{\circ} \mathrm{C}$ until further use.

The mixtures were identified as Honey 1 followed by the corresponding Propolis Extract and percentage added resulting in Honey 1-Propolis Extract 1 (H1PE1), Honey 1-Propolis Extract 2 (H1PE2) and Honey 1-Propolis Extract 3 (H1PE3) at $0.3 \%$ or $0.5 \%$.

\subsection{Fourier-Transform Infrared Spectroscopy (FTIR)}

FTIR was used to obtain spectra of the samples of honey, propolis and propolis extracts. These spectra were obtained with 64 scans and a $4 \mathrm{~cm}^{-1}$ resolution, between 4000 and $600 \mathrm{~cm}^{-1}$ using a Nicolet iS10 smart iTRBasic (Thermo Fisher Scientific, Waltham, MA, USA) model.

\subsection{Phytochemical Characterization}

For the phytochemical characterization, all the samples were diluted with methanol (Scharlab, Spain).

\subsubsection{Total Phenolic Compounds Determination}

The phenolic compounds were determined by Folin-Ciocalteu's colorimetric method $[14,15]$, using gallic acid as the standard. Initially, $450 \mu \mathrm{L}$ of distilled water were mixed with $50 \mu \mathrm{L}$ of each sample or gallic acid (Sigma-Aldrich, USA) solution. Then, $2.5 \mathrm{~mL}$ of Folin-Ciocalteu's reagent (Sigma-Aldrich, USA) $(0.2 \mathrm{~N})$ were added, being the mixtures left for $5 \mathrm{~min}$ before the addition of $2 \mathrm{~mL}$ of aqueous $\mathrm{Na}_{2} \mathrm{CO}_{3}$ (Sigma-Aldrich, USA) $(75 \mathrm{~g} / \mathrm{L}$ ). The reaction mixtures were incubated for $90 \mathrm{~min}$ at $30^{\circ} \mathrm{C}$. After incubation, the content in total phenolic compounds was determined by colorimetry at $765 \mathrm{~nm}[14,15]$.

A standard curve was prepared using methanolic solutions of gallic acid at 500, 300, 250, 200, 150, 100 , and $50 \mathrm{mg} / \mathrm{L}\left(\mathrm{y}=0.0010 \mathrm{x} ; \mathrm{R}^{2}=0.9612\right)$. The total phenolic compounds content was expressed as $\mathrm{g}$ of gallic acid equivalents (GAE)/100 $\mathrm{g}$ of sample (honey, propolis, and mixtures of honey with propolis) [14,15].

\subsubsection{Flavonoid Determination}

The aluminum chloride colorimetric method was used to determine the flavonoids content according to a previously implemented method [14,15]. To $500 \mu \mathrm{L}$ of each solution, either the samples or the quercetin (Sigma-Aldrich, USA) (used as standard), $1.5 \mathrm{~mL}$ of methanol, $0.1 \mathrm{~mL}$ of aluminum chloride (Sigma-Aldrich, USA) 10\% (w/v), $0.1 \mathrm{~mL}$ of $1 \mathrm{M}$ potassium acetate (Sigma-Aldrich, USA) and $2.8 \mathrm{~mL}$ of distilled water were added. These solutions remained for $30 \mathrm{~min}$ at room temperature and then the absorbances were measured using a spectrophotometer (Helios-Omega, Thermo Scientific, USA) at $415 \mathrm{~nm}[14,15]$.

To construct the calibration curve, eight quercetin solutions were prepared in methanol with a concentration of $200,175,150,100,75,50,25$, and $12.5 \mu \mathrm{g} / \mathrm{mL}\left(\mathrm{y}=0.0146 \mathrm{x} ; \mathrm{R}^{2}=0.9887\right)$. The flavonoids 
content was expressed as $g$ of quercetin equivalents $(\mathrm{QE}) / 100 \mathrm{~g}$ of sample (honey, propolis, and mixtures of honey with propolis) [14,15].

\subsection{Antioxidant Activity Evaluation}

For the antioxidant activity evaluation all the samples were diluted with methanol.

\subsubsection{DPPH Free Radical Scavenging Assay}

The DPPH (2,2-diphenyl-1-picrylhydrazyl) free radical scavenging assay was used to evaluate the antioxidant activity of the samples [16]. Briefly, to $100 \mu \mathrm{L}$ of each sample, $3.9 \mathrm{~mL}$ of a $0.1 \mathrm{mM}$ DPPH (Sigma-Aldrich, USA) methanolic solution were added, being this mixture stirred until complete homogenization. The control solution consisted in $100 \mu \mathrm{L}$ of methanol with $3.9 \mathrm{~mL}$ of the DPPH solution. The reaction mixtures were kept at room temperature in the absence of light for $30 \mathrm{~min}$, time after which the absorbances were read at $517 \mathrm{~nm}$ using a spectrophotometer (Helios-Omega, Thermo Scientific, USA) [16].

The percentage of inhibition (\%Inhibition) of DPPH free radical by the samples was determined using the equation \%Inhibition $=\left[\left(\mathrm{Abs}_{\mathrm{control}}-\mathrm{Abs}_{\text {ample }}\right) / \mathrm{Abs}_{\mathrm{control}}\right] \times 100$, where $\mathrm{Abs}_{\text {control }}$ corresponds to the absorbance of the control and $\mathrm{Abs}_{\text {sample }}$ is the absorbance of each sample $[14,15]$. The results were expressed as \%Inhibition/100 g sample (honey, propolis, and mixtures of honey with propolis).

\subsection{2. $\beta$-Carotene Bleaching Test}

The $\beta$-carotene bleaching test was also employed to evaluate the antioxidant properties of the samples [16]. Firstly, a $\beta$-carotene (Sigma-Aldrich, USA) solution in chloroform with a concentration of $20 \mathrm{mg} / \mathrm{mL}$ was prepared. To $500 \mu \mathrm{L}$ of this solution $40 \mu \mathrm{L}$ of linoleic acid (TCI Europe N.V., Belgium), $400 \mu \mathrm{L}$ of Tween 40 (Riedel-de H"aen, Germany) and $1 \mathrm{~mL}$ of chloroform (Scharlab, Spain) were added. This mixture was transferred to a round bottom flask and subjected to a rotary evaporation system at $45^{\circ} \mathrm{C}$ to ensure complete evaporation of the chloroform. After this, $100 \mathrm{~mL}$ of water saturated with oxygen were added to the mixture, forming an emulsion. Secondly, $300 \mu \mathrm{L}$ of each sample were transferred to test tubes and $5 \mathrm{~mL}$ of the previously prepared $\beta$-carotene emulsion were added. The tubes were stirred until complete homogenization and were placed in a water bath at $50^{\circ} \mathrm{C}$ for $1 \mathrm{~h}$. Using a spectrophotometer (Helios-Omega, Thermo Scientific, USA), the absorbances of the samples were measured at $470 \mathrm{~nm}$ at the initial $(\mathrm{t}=0 \mathrm{~h})$ and final time $(\mathrm{t}=1 \mathrm{~h})$. The antioxidant activity was determined as percentage of inhibition of $\beta$-carotene's oxidation (\%Inhibition) using the following equation, \%Inhibition $=\left[\left(\mathrm{Abs}_{\text {sample }}{ }^{\mathrm{t}=1 \mathrm{~h}}-\mathrm{Abs}_{\text {control }} \mathrm{t}=1 \mathrm{~h}\right) /\left(\mathrm{Abs}_{\text {control }} \mathrm{t}=0 \mathrm{~h}-\mathrm{Abs}_{\text {control }} \mathrm{t}=1 \mathrm{~h}\right)\right] \times 100$, where $\mathrm{Abs}_{\text {control }}$ corresponds to the absorbance of the control and $\mathrm{Abs}_{\text {sample }}$ is the absorbance of each sample $[14,15]$. The results were expressed as \%Inhibition/100 g sample (honey, propolis, and mixtures of honey with propolis).

\subsection{Assessment of In Vitro Anti-Inflammatory Activity}

The anti-inflammatory activity was determined by evaluating the capacity of the samples to inhibit protein denaturation [17]. Initially, a solution of bovine serum albumin (BSA) (Sigma-Aldrich, USA) at $1 \%(\mathrm{w} / \mathrm{v})$ in phosphate buffer saline (PBS) solution was prepared. The $\mathrm{pH}$ of this solution was adjusted to 6.8 using glacial acetic acid (Scharlab, Spain). Then, $100 \mu \mathrm{L}$ of the samples diluted in methanol were mixed, in test tubes pre-heated at $37^{\circ} \mathrm{C}$, with $900 \mu \mathrm{L}$ of the BSA solution previously prepared. The control was composed of distilled water. The tubes were then incubated for $10 \mathrm{~min}$ at $72{ }^{\circ} \mathrm{C}$ and after this period cooled in ice for another $10 \mathrm{~min}$. Finally, measurements of the absorbances were performed using a spectrophotometer (Helios-Omega, Thermo Scientific, USA) at $620 \mathrm{~nm}$. The percentage of inhibition of protein denaturation (\%Inhibition) was determined applying the following equation, $\%$ Inhibition $=100-\left[\left(\mathrm{Abs}_{\text {sample }} \times 100\right) / \mathrm{Abs}_{\text {control }}\right]$, where $\mathrm{Abs}_{\text {control }}$ corresponds to the absorbance of the control and $\mathrm{Abs}_{\text {sample }}$ is the absorbance of each sample [17]. The results were expressed as \%Inhibition/100 g sample (honey, propolis, and mixtures of honey with propolis). 


\subsection{Evaluation of the In Vitro Wound-Healing Activity}

\subsubsection{Cell Culture}

Normal human dermal fibroblasts (NHDF) cell line was maintained in RPMI-1640 culture medium (Sigma-Aldrich, USA) supplemented with 10\% fetal bovine serum (FBS) (Sigma-Aldrich, USA), 1\% mixture of antibiotic/antimycotic (Sigma-Aldrich, USA), 0.01 M of HEPES (Sigma-Aldrich, USA), $0.02 \mathrm{M}$ of $L$-glutamine (Sigma-Aldrich, USA) and $0.001 \mathrm{M}$ of sodium pyruvate (Sigma-Aldrich, USA). Subsequently, the cells were incubated at $37^{\circ} \mathrm{C}$ in an air incubator with a humidified atmosphere with $5 \% \mathrm{CO}_{2}[18]$.

\subsubsection{Wound Scratch Assay}

The samples were tested for wound-healing activity by using the wound scratch assay $[13,19]$. NHDF cells were seeded in 12 -well plates $\left(4 \times 10^{4}\right.$ cells/well) and cultured until a monolayer confluence was reached. After the adhesion of the cells, the medium was removed from the wells and the cell monolayer was scraped in a straight central line using a p200 micropipette tip, creating a scratch, with reference points being marked in the plates. The wells were washed with PBS to remove floating cells and cell debris. Then, the PBS was removed, the samples were prepared in RPMI-1640 and sonicated, then they were added to the wells. Supplemented RPMI-1640 culture medium was added to the control wells. After this, the plates were placed under a phase-contrast microscope and images were acquired at the initial moment $(\mathrm{t}=0 \mathrm{~h})$. Then, the plates were incubated at $37{ }^{\circ} \mathrm{C}\left(5 \% \mathrm{CO}_{2}\right)$ and examined once again under the microscope after 2, 24, and $36 \mathrm{~h}[13,19]$.

The size of the scratch zones was assessed manually using a digital image analysis tool (IC Measure software version 2.0.0.161) (The Imaging Source, Germany) that allowed the estimation of the distance between the injury margins. Using the IC Measure, the distance between the margins of the lesion in the control at $0 \mathrm{~h}$ was estimated, which was considered the initial one and was used to scale all other measurements to more easily compare the estimated distances of the injuries between the samples and the control.

\subsection{Statistical Analysis}

The results were presented as mean values \pm standard deviation. To determine the reproducibility of the measurements, each assay was performed at least in triplicate. The calculated distance between the margins of the injury were analyzed using the statistical program IBM SPSS Statistics 25 (https://www.ibm.com/analytics/spss-statistics-software) (IBM, Armonk, NY, USA). The significant difference among means was analyzed by Student's $t$-test (assuming the normal distribution of the continuous variables). A level of $p$-value $<0.05$ was considered significant.

\section{Results and Discussion}

\subsection{FTIR Analysis of the Samples of Honey, Propolis, and Propolis Extracts}

Regarding the honey samples and given the flora that exists at the place of harvest, it is expected that Honey 1 was produced mainly during the autumn from species such as Arbutus unedo, Castanea sativa, Quercus faginea, and Pinus pinaster. Honey 2 was produced during the summer from flowers such as Rosa spp., Dahlia spp., Hydrangea spp., and flowers from fruit trees like Prunus avium, Malus spp., Pyrus communis, and Prunus spinosa. Finally, Honey 3 was produced during the spring, when most wildflowers and aromatic plants bloom (Papaver rhoeas, Chrysanthemum coronarium, Lavandula stoechas, Rosmarinus officinalis, Baccharis trimera, and Thymus mastichina).

The propolis samples subsequently collected did not show a direct correlation with the honey samples, because bees repair their hive continuously throughout the year, whenever this need arises, so the conditions under which propolis is produced will not necessarily be the same conditions under which honey is produced. 
The FTIR spectra of the samples of honey, propolis, and propolis extracts were recorded (Figure 1).

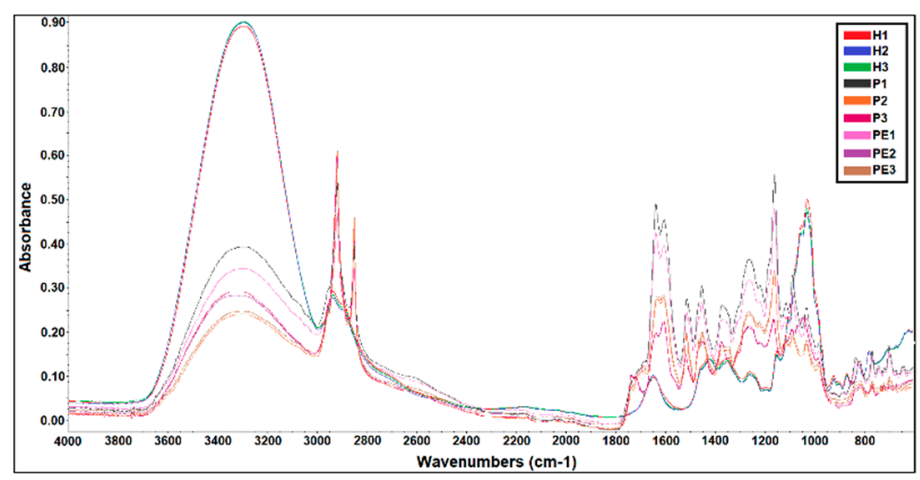

Figure 1. FTIR spectra of the samples.

The spectra of honeys show a water band at approximately $3300 \mathrm{~cm}^{-1}$ and $1650 \mathrm{~cm}^{-1}$. Near $2900 \mathrm{~cm}^{-1}$ it is possible to observe a band that may be associated with groups present in amino acids. The bands between 1450 and $750 \mathrm{~cm}^{-1}$ may correspond to organic acids and to sugars commonly present in honey, such as sucrose, glucose, and fructose. Even though the honey samples have been produced in different seasons, they present quite similar spectra.

The spectra of propolis samples show approximately the same bands but with great dissimilarity in terms of the intensity of the signal. In these spectra, it can be observed a water band at around $3400 \mathrm{~cm}^{-1}$, and very pronounced bands at nearly 2900 and $2850 \mathrm{~cm}^{-1}$ that may correspond to some aliphatic compounds. The bands observed between 1650 and $1600 \mathrm{~cm}^{-1}$, as well as the bands between 1550 and $1400 \mathrm{~cm}^{-1}$ may be caused by the presence of flavonoids and other aromatic compounds. The band at $1150 \mathrm{~cm}^{-1}$ may be due to the presence of hydroxyflavonoids. Some of the bands were not considered and may be related to wax and other debris present in the samples. The spectra of propolis extracts show approximately the same bands, but with lower intensity than the propolis samples.

The water band observed in both propolis samples and extracts is less pronounced than the band registered in the honeys. In contrast, the bands identified as possible aromatic compounds and flavonoids in propolis samples and extracts spectra are more pronounced. Finally, the sugar bands in honey spectra are more evident and better outlined.

The results now obtained are in agreement with other previously published results for other honey and propolis samples [20,21].

\subsection{Phytochemical Characterization}

Plant polyphenols present at least 8000 distinct known structures, being the most important class of natural bioactive compounds, which exhibit various biological activities [22]. Honey presents three classes of flavonoids with analogous structure: flavonols, flavones, and flavanones. Flavonoids are responsible for the color, taste, and flavor of the honey and they also improve its beneficial health effects [22]. Furthermore, the floral sources used by bees to produce honey, whose predominance depends on seasonal and environmental issues, influences the phenolic composition and antioxidant activity of honey.

The results of the phytochemical characterization of the samples regarding total phenolics and flavonoids contents are presented in Table 1. 
Table 1. Total phenolic compounds and flavonoids content of the samples.

\begin{tabular}{ccc}
\hline \multirow{2}{*}{ Samples } & Total Phenolic Compounds & Flavonoids \\
\cline { 2 - 3 } & (g GAE/100 g Sample) $^{\mathbf{1}}$ & (g QE/100 g Sample) $^{\mathbf{1}}$ \\
\hline H1 & $0.107 \pm 0.016$ & $0.007 \pm 0.001$ \\
H2 & $0.046 \pm 0.005$ & Not detected \\
H3 & $0.029 \pm 0.003$ & Not detected \\
PE1 & $28.947 \pm 1.329$ & $5.494 \pm 0.335$ \\
PE2 & $21.747 \pm 1.062$ & $1.786 \pm 0.029$ \\
PE3 & $28.667 \pm 0.774$ & $4.280 \pm 0.123$ \\
H1PE1 0.3\% & $2.394 \pm 0.227$ & $0.290 \pm 0.007$ \\
H1PE1 0.5\% & $3.324 \pm 0.044$ & $0.452 \pm 0.012$ \\
H1PE2 0.3\% & $1.219 \pm 0.049$ & $0.115 \pm 0.005$ \\
H1PE2 0.5\% & $1.750 \pm 0.076$ & $0.199 \pm 0.018$ \\
H1PE3 0.3\% & $1.969 \pm 0.071$ & $0.054 \pm 0.011$ \\
H1PE3 0.5\% & $3.506 \pm 0.257$ & $0.308 \pm 0.006$ \\
\hline
\end{tabular}

${ }^{1}$ Results expressed as mean \pm standard deviation.

Total phenolic compounds content of honey samples ranged from 0.029 to $0.107 \mathrm{~g} \mathrm{GAE} / 100 \mathrm{~g}$ sample, the values observed for propolis extracts ranged from 21.747 to $28.947 \mathrm{~g} \mathrm{GAE} / 100 \mathrm{~g}$ sample, and finally for the mixtures of honey with propolis ranged from 1.219 to $3.506 \mathrm{~g}$ GAE/100 $\mathrm{g}$ sample. The honey that presented the highest content in phenolic compounds is Honey 1 and the lowest content can be found in Honey 3. These differences may be related with the different seasons in which the honeys were produced, as mentioned above.

Propolis extracts showed a much higher concentration of phenolic compounds than honey samples, with the highest content found in Propolis Extract 1 followed by Propolis Extract 3 and Propolis Extract 2. An increase in phenolic content was observed with the addition of higher concentrations of propolis extracts to honey, and the highest value was obtained with H1PE3 at $0.5 \%$.

Flavonoids were almost absent from honey samples. The only one that presents flavonoids in its composition is Honey 1 , but even this sample has a very low content. In contrast, the flavonoids determined in the propolis extracts ranged from 1.786 to $5.494 \mathrm{~g} \mathrm{QE} / 100 \mathrm{~g}$ sample, and in the mixtures ranged from 0.054 to $0.452 \mathrm{~g} Q E / 100 \mathrm{~g}$ sample. Propolis extracts showed a higher concentration of flavonoids than honey samples, with the highest content in Propolis Extract 1 followed by Propolis Extract 3 and Propolis Extract 2. An increase in flavonoid content was observed in all samples with the addition of higher concentrations of propolis extract to honey, as expected.

The values of total phenolic compounds and flavonoids determined in the present work are very similar to the ones obtained for selected Czech honeys [23].

\subsection{Antioxidant and Anti-Inflammatory Activities}

Honey is an important natural source of antioxidants and has potential therapeutic value in several inflammatory diseases and in the treatment of heart disease, cancer, and cataracts, in addition to its sweetening capacity and lower glycemic load [24]. The biological properties of honey comprise antioxidant, antimicrobial, anti-inflammatory, and wound-healing activities [24].

In this work, the antioxidant activity of the samples was evaluated by two different methods that measure distinct antioxidant properties (Table 2). The DPPH free radical scavenging assay is based on the capacity of the samples to scavenge free radicals, while the $\beta$-carotene bleaching test allows the indirect evaluation of the capacity of the samples to inhibit the lipid peroxidation [25]. 
Table 2. Antioxidant and anti-inflammatory activities of the samples.

\begin{tabular}{|c|c|c|c|}
\hline \multirow{2}{*}{ Samples } & DPPH & $\beta$-Carotene Bleaching Test & Anti-Inflammatory Activity \\
\hline & $\%$ Inhibition/100 g Sample ${ }^{1}$ & $\%$ Inhibition/100 g Sample ${ }^{1}$ & $\%$ Inhibition/100 g Sample ${ }^{1}$ \\
\hline H1 & $0.431 \pm 0.023$ & $0.809 \pm 0.042$ & $20.625 \pm 0.884$ \\
\hline $\mathrm{H} 2$ & $0.133 \pm 0.019$ & $0.684 \pm 0.032$ & $23.438 \pm 3.094$ \\
\hline H3 & Not detected & $0.349 \pm 0.028$ & Not detected \\
\hline PE1 & $92.506 \pm 1.249$ & $51.441 \pm 4.477$ & $15.000 \pm 3.536$ \\
\hline PE2 & $92.012 \pm 0.258$ & $48.660 \pm 1.876$ & $31.250 \pm 1.768$ \\
\hline PE3 & $93.245 \pm 0.687$ & $53.909 \pm 2.328$ & $48.750 \pm 1.768$ \\
\hline H1PE1 0.3\% & $8.271 \pm 0.044$ & $3.027 \pm 0.070$ & $36.408 \pm 6.865$ \\
\hline H1PE1 0.5\% & $8.119 \pm 0.040$ & $3.929 \pm 0.105$ & $28.571 \pm 0.001$ \\
\hline H1PE2 $0.3 \%$ & $7.921 \pm 0.097$ & $2.878 \pm 0.096$ & $40.049 \pm 1.716$ \\
\hline H1PE2 $0.5 \%$ & $8.154 \pm 0.158$ & $3.108 \pm 0.049$ & $45.238 \pm 0.001$ \\
\hline H1PE3 0.3\% & $8.165 \pm 0.026$ & $2.919 \pm 0.106$ & $36.408 \pm 3.433$ \\
\hline H1PE3 0.5\% & $8.396 \pm 0.321$ & $3.596 \pm 0.089$ & $40.476 \pm 6.734$ \\
\hline
\end{tabular}

The honey that presented the highest antioxidant activity measured by the DPPH assay was Honey 1, opposed to Honey 3 that showed no relevant activity measured by this method. Propolis extracts revealed extremely high levels of antioxidant activity across all samples, with Propolis Extract 3 presenting the highest value. An increase in the antioxidant activity was observed in all samples with the addition of propolis extract to honey, however adding a higher concentration of propolis did not result in a considerable rase in activity in most cases.

Concerning the results of $\beta$-carotene bleaching test, the honey that revealed the highest antioxidant activity was once again Honey 1 . The antioxidant activity of this honey measured by both methods is related with the presence of great amounts of phenolic compounds, as previously mentioned. Propolis extracts revealed high levels of antioxidant activity measured by $\beta$-carotene bleaching test as it was also verified by DPPH assay.

Analyzing the data obtained throughout the different assays it was possible to verify that dark-brown honey (H1) presented a higher content in phenolic compounds and flavonoids, followed by red honey (H2) and finally by light-yellow honey (H3). These results were consistent with the bioactive activity of the different samples. Since Honey 1 presented better phytochemical results, it was used in all the mixtures of honey with propolis.

The anti-inflammatory activity was evaluated using an in vitro assay that studied the ability of the samples to inhibit protein denaturation using a BSA solution (Table 2). It was noted that propolis extracts reveal a higher anti-inflammatory activity than honeys. The honey that presented the highest activity was Honey 2, and among the Propolis Extracts, PE3 revealed the highest activity. Generally, an increase in the anti-inflammatory activity was observed in all samples when adding propolis extract to honey. In a previous work involving Malaysian honeys, the authors concluded that the anti-inflammatory activity may be attributed, at least in part, to the phenolic compounds [24].

\subsection{Wound-Healing Activity}

In the present study, NHDF cells were used in a scratch assay. Although all the preliminary characterization data showed that the propolis extracts always presented better results than the other samples under study, it was decided to also evaluate the wound-healing activity for all the samples including the mixtures of honey with propolis.

It is already known that honey is not toxic against normal cells but is extremely cytotoxic to the tumor or cancer cells, as it was previously described [26]. Similar results were found in propolis extracts, which demonstrated cytotoxicity in human fibrosarcoma and colon adenocarcinoma cells while presenting no cytotoxic action in normal human skin fibroblasts [27].

By using the microscopic images, it was possible to evaluate the evolution of the gap created in the confluent cell monolayer in the presence of the samples (Table 3, Table 4, and Table 5). 
Analyzing the different images and comparing them to the control samples it is possible to say that the honey that shows better results after $36 \mathrm{~h}$ is Honey 2 (Table 3), while the propolis extract that presented better results was Propolis Extract 2 at $0.5 \%$ (Table 4); the best mixture is the honey with propolis-H1PE3 0.3\% (Table 5).

Examining all the images, it is possible to observe that the cells continue alive when incubated with the samples. Moreover, it is clear that the samples promote cell migration, demonstrating the wound-healing potential of honey and propolis.

Furthermore, by estimating the distance between the margins of the scratch (Table 6) the conclusions were the same. For all the samples, except for Honey 3 at 2 h, a significant $(p$-value $<0.05)$ reduction of the scratch was observed when compared to the control at the same time of incubation. In general, the samples that showed the best results were the mixtures of honey with propolis. However, the sample that presented the maximum activity was the Propolis Extract 2 at $0.5 \%$.

Table 3. Microscopic images obtained from the scratch wound-healing assay with the honeys (magnification: $100 \times$ ).

\section{Representative Image of the Cells at the Initial Moment $(0 \mathrm{~h})$}

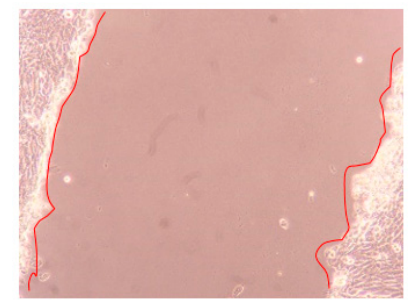

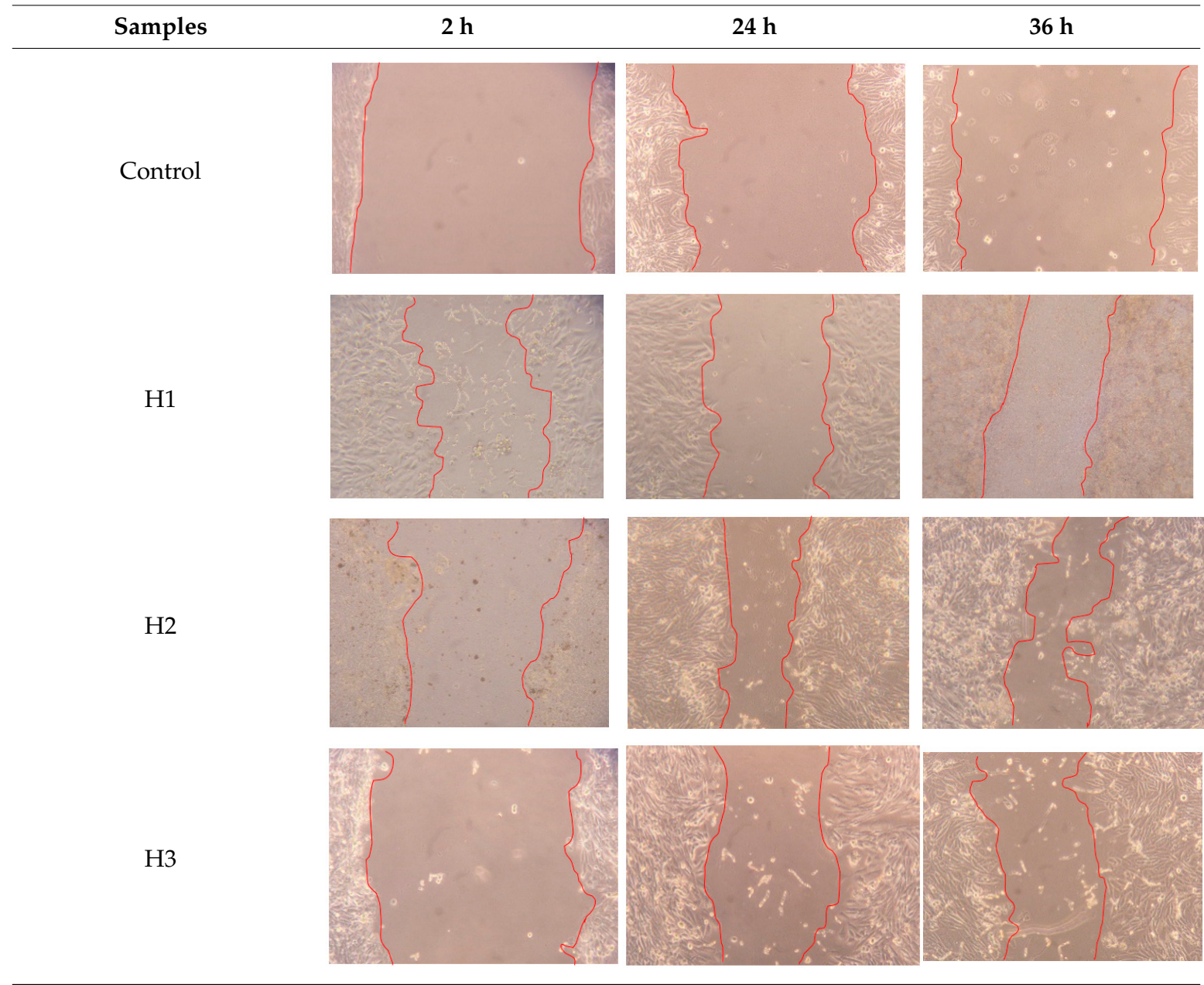


Table 4. Microscopic images obtained from the scratch wound-healing assay with the propolis extracts (magnification: 100×).

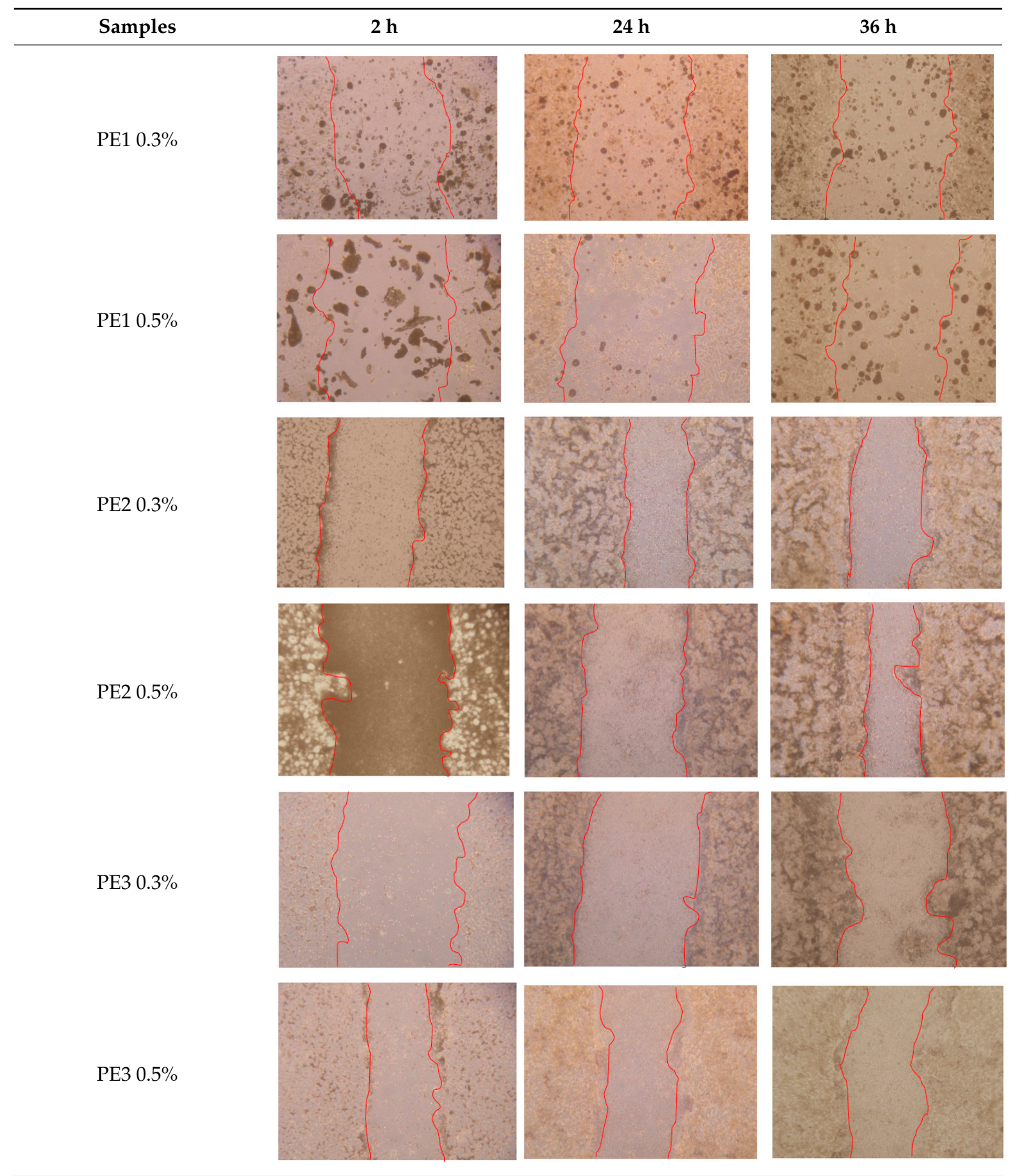


Table 5. Microscopic images obtained from the scratch wound-healing assay with the mixtures of honey with propolis (magnification: 100×).

\begin{tabular}{|c|c|c|c|}
\hline Samples & $2 \mathrm{~h}$ & $24 \mathrm{~h}$ & $36 \mathrm{~h}$ \\
\hline H1PE1 $0.3 \%$ & & & \\
\hline H1PE1 0.5\% & & & \\
\hline H1PE2 0.3\% & & & \\
\hline H1PE2 0.5\% & & & \\
\hline H1PE3 0.3\% & & & \\
\hline H1PE3 0.5\% & & & \\
\hline
\end{tabular}

In opposition to what was previously observed [1], in the present work the obtained results suggest that the effect of combining propolis with honey is not synergistic but just the combined effect of honey and propolis. This may be due to the chemical composition of each particular honey that will directly influence its bioactivities. In the honey samples now studied, the concentration in total phenolic compounds is relatively lower than in other samples of honey [1]. Moreover, flavonoids were not detected in the honey samples. These observations may explain the additive results observed for the mixtures of honey with propolis, suggesting the contribution of the propolis compounds to the biological activities.

Considering all the obtained results, it is possible to verify that the samples that presented higher cell migration levels also presented higher bioactivity. 
During the inflammation process, honey promotes the release of inflammatory cytokines (TNF- $\alpha$ IL-6, IL-1 $\beta$, and NO) by monocytes, which might stimulate collagen synthesis by fibroblasts, playing important roles in the initiation and amplification of this process [10]. The modulation of the severity of inflammation can be associated with the anti-inflammatory properties of the polyphenols present in honey. Honey initiates an active but controlled inflammation but does not let the inflammation to develop in a chronic or exaggerated state, modulating the inflammatory phase of wound-healing [10]. The anti-ulcerous activity of honey and propolis can be attributed to flavonoids that can act alone or in combination with other compounds such as sterols, terpinens, saponins, gums, and mucilage [4].

A recently published paper, in which the potential wound-healing properties of propolis was evaluated, demonstrated that propolis promoted a marked increase in the wound repair capacity of keratinocytes [28]. It was also proved that the regenerative properties of propolis are mainly due to $\mathrm{H}_{2} \mathrm{O}_{2}$ (which is extracellularly released and passes across the plasma membrane) is able to modulate intracellular mechanisms [28].

Table 6. Calculated distance between the margins of the injury.

\begin{tabular}{|c|c|c|c|c|c|c|c|}
\hline Samples & $0 \mathrm{~h}^{1}$ & $2 h^{1}$ & $p$-Value & $24 h^{1}$ & $p$-Value & $36 h^{1}$ & $p$-Value \\
\hline Control & & $0.99 \pm 0.05$ & 0.818 & $0.99 \pm 0.05$ & 1.000 & $0.98 \pm 0.05$ & 0.817 \\
\hline H1 & & $0.71 \pm 0.04$ & $0.002 *$ & $0.59 \pm 0.03$ & $0.001 *$ & $0.48 \pm 0.02$ & $0.001 *$ \\
\hline $\mathrm{H} 2$ & & $0.83 \pm 0.04$ & 0.011 * & $0.37 \pm 0.02$ & $0.001 *$ & $0.33 \pm 0.02$ & 0.001 * \\
\hline H3 & & $0.90 \pm 0.05$ & 0.062 & $0.57 \pm 0.03$ & $0.001 *$ & $0.49 \pm 0.02$ & $0.001 *$ \\
\hline PE1 0.3\% & & $0.80 \pm 0.04$ & $0.006^{*}$ & $0.78 \pm 0.04$ & $0.005 *$ & $0.69 \pm 0.03$ & $0.002 *$ \\
\hline PE1 0.5\% & & $0.84 \pm 0.04$ & 0.014 * & $0.81 \pm 0.04$ & $0.009 *$ & $0.78 \pm 0.04$ & 0.005 * \\
\hline PE2 $0.3 \%$ & & $0.54 \pm 0.03$ & $0.001 *$ & $0.39 \pm 0.02$ & $0.001 *$ & $0.34 \pm 0.02$ & $0.001 *$ \\
\hline PE2 $0.5 \%$ & 0.05 & $0.66 \pm 0.03$ & $0.001 *$ & $0.52 \pm 0.03$ & $0.001 *$ & $0.27 \pm 0.01$ & $0.001 *$ \\
\hline PE3 0.3\% & $=0.05$ & $0.74 \pm 0.04$ & $0.003 *$ & $0.62 \pm 0.03$ & $0.001 *$ & $0.53 \pm 0.03$ & 0.001 * \\
\hline PE3 $0.5 \%$ & & $0.45 \pm 0.02$ & 0.001 * & $0.41 \pm 0.02$ & $0.001 *$ & $0.39 \pm 0.02$ & 0.001 * \\
\hline H1PE1 0.3\% & & $0.74 \pm 0.04$ & $0.003 *$ & $0.63 \pm 0.03$ & $0.001 *$ & $0.55 \pm 0.03$ & 0.001 * \\
\hline H1PE1 0.5\% & & $0.43 \pm 0.02$ & $0.001 *$ & $0.43 \pm 0.02$ & $0.001 *$ & $0.42 \pm 0.02$ & 0.001 * \\
\hline H1PE2 0.3\% & & $0.54 \pm 0.03$ & 0.001 * & $0.37 \pm 0.02$ & $0.001 *$ & $0.49 \pm 0.02$ & $0.001 *$ \\
\hline H1PE2 0.5\% & & $0.64 \pm 0.03$ & $0.001 *$ & $0.58 \pm 0.03$ & $0.001 *$ & $0.46 \pm 0.02$ & $0.001 *$ \\
\hline H1PE3 0.3\% & & $0.80 \pm 0.04$ & $0.006 *$ & $0.44 \pm 0.02$ & $0.001 *$ & $0.31 \pm 0.02$ & 0.001 * \\
\hline H1PE3 0.5\% & & $0.74 \pm 0.04$ & $0.001 *$ & $0.45 \pm 0.02$ & $0.001 *$ & $0.34 \pm 0.02$ & 0.001 * \\
\hline
\end{tabular}

${ }^{1}$ Results expressed as mean \pm standard deviation; * Indicates a significant result ( $p$-value $\left.<0.05\right)$.

\section{Conclusions}

This work demonstrated the biological potential of honey and propolis, particularly the wound-healing activity, which is related with their antioxidant and anti-inflammatory properties. Further studies should be performed to clarify the mechanism of action of honey and propolis by which cell migration is stimulated.

Author Contributions: Conceptualization, A.P.D.; methodology, A.M.A., J.G., and Â.L.; Formal analysis, E.G. and A.P.D.; Investigation, A.M.A., J.G., and Â.L.; Resources, E.G. and A.P.D.; Data curation, E.G. and A.P.D.; Writing—original draft preparation, A.M.A.; Writing—review and editing, J.G., Â.L., E.G., and A.P.D.; Supervision, A.P.D. All authors have read and agreed to the published version of the manuscript.

Funding: This work was partially supported by CICS-UBI that is financed by National Funds from Fundação para a Ciência e a Tecnologia (FCT) and Community Funds (UIDB/00709/2020). Joana Gonçalves acknowledges the PhD fellowship from FCT (reference: SFRH/BD/149360/2019). Ângelo Luís acknowledges the contract of Scientific Employment in the scientific area of Microbiology also financed by FCT.

Conflicts of Interest: The authors declare no conflict of interest.

\section{References}

1. Osés, S.M.; Pascual-Maté, A.; Fernández-Muiño, M.A.; López-Díaz, T.M.; Sancho, M.T. Bioactive properties of honey with propolis. Food Chem. 2016, 196, 1215-1223. [CrossRef] 
2. Liu, J.R.; Ye, Y.L.; Lin, T.Y.; Wang, Y.W.; Peng, C.C. Effect of floral sources on the antioxidant, antimicrobial, and anti-inflammatory activities of honeys in Taiwan. Food Chem. 2013, 139, 938-943. [CrossRef] [PubMed]

3. Ferreira, I.C.F.R.; Aires, E.; Barreira, J.C.M.; Estevinho, L.M. Antioxidant activity of Portuguese honey samples: Different contributions of the entire honey and phenolic extract. Food Chem. 2009, 114, 1438-1443. [CrossRef]

4. Viuda-Martos, M.; Ruiz-Navajas, Y.; Fernández-López, J.; Pérez-Álvarez, J.A. Functional properties of honey, propolis, and royal jelly. J. Food Sci. 2008, 73, 117-124. [CrossRef] [PubMed]

5. Cianciosi, D.; Forbes-Hernández, T.Y.; Afrin, S.; Gasparrini, M.; Reboredo-Rodriguez, P.; Manna, P.P.; Zhang, J.; Lamas, L.B.; Flórez, S.M.; Toyos, P.A.; et al. Phenolic compounds in honey and their associated health benefits: A review. Molecules 2018, 23, 2322. [CrossRef]

6. Sforcin, J.M. Propolis and the immune system: A review. J. Ethnopharmacol. 2007, 113, 1-14. [CrossRef]

7. Anjum, S.I.; Ullah, A.; Khan, K.A.; Attaullah, M.; Khan, H.; Ali, H.; Bashir, M.A.; Tahir, M.; Ansari, M.J.; Ghram, H.A.; et al. Composition and functional properties of propolis (bee glue): A review. Saudi J. Biol. Sci. 2019, 26, 1695-1703. [CrossRef]

8. Zabaiou, N.; Fouache, A.; Trousson, A.; Baron, S.; Zellagui, A.; Lahouel, M.; Lobaccaro, J.A. Biological properties of propolis extracts: Something new from an ancient product. Chem. Phys. Lipids 2017, 207, 214-222. [CrossRef]

9. Silva-Carvalho, R.; Baltazar, F.; Almeida-Aguiar, C. Propolis: A complex natural product with a plethora of biological activities that can be explored for drug development. Evid.-Based Complement. Altern. Med. 2015, 2015, 206439. [CrossRef]

10. Oryan, A.; Alemzadeh, E.; Moshiri, A. Biological properties and therapeutic activities of honey in wound healing: A narrative review and meta-analysis. J. Tissue Viability 2016, 25, 98-118. [CrossRef]

11. Martinotti, S.; Ranzato, E. Propolis: A new frontier for wound healing? Burn. Trauma 2015, 3, 9. [CrossRef] [PubMed]

12. Kalogeropoulos, N.; Konteles, S.J.; Troullidou, E.; Mourtzinos, I.; Karathanos, V.T. Chemical composition, antioxidant activity and antimicrobial properties of propolis extracts from Greece and Cyprus. Food Chem. 2009, 116, 452-461. [CrossRef]

13. Felician, F.F.; Yu, R.; Li, M.; Li, C.; Chen, H.; Jiang, Y.; Tang, T.; Qi, W.; Xu, H. The wound healing potential of collagen peptides derived from the jellyfish Rhopilema esculentum. Chin. J. Traumatol. 2019, 22, 12-20. [CrossRef] [PubMed]

14. Luís, Â.; Sousa, S.; Duarte, A.P.; Pereira, L.; Domingues, F. Phytochemical characterization, and evaluation of rheological and antioxidant properties of commercially available juices of berries. J. Berry Res. 2018, 8, 11-23. [CrossRef]

15. Luís, Â.; Neiva, D.; Pereira, H.; Gominho, J.; Domingues, F.; Duarte, A.P. Stumps of Eucalyptus globulus as a source of antioxidant and antimicrobial polyphenols. Molecules 2014, 19, 16428-16446. [CrossRef]

16. Luís, Â.; Duarte, A.P.; Pereira, L.; Domingues, F. Interactions between the major bioactive polyphenols of berries: Effects on antioxidant properties. Eur. Food Res. Technol. 2018, 244, 175-185. [CrossRef]

17. Luís, Â.; Sousa, S.; Wackerlig, J.; Dobusch, D.; Duarte, A.P.; Pereira, L.; Domingues, F. Star anise (Illicium verum Hook. f.) essential oil: Antioxidant properties and antibacterial activity against Acinetobacter baumannii. Flavour Fragr. J. 2019, 34, 260-270. [CrossRef]

18. Luís, Â.; Breitenfeld, L.; Ferreira, S.; Duarte, A.P.; Domingues, F. Antimicrobial, antibiofilm and cytotoxic activities of Hakea sericea Schrader extracts. Pharmacogn. Mag. 2014, 10, S6-S13.

19. Liang, C.-C.; Park, A.Y.; Guan, J.-L. In vitro scratch assay: A convenient and inexpensive method for analysis of cell migration in vitro. Nat. Protoc. 2007, 2, 329-333. [CrossRef]

20. Oliveira, R.N.; Mancini, M.C.; Oliveira, F.C.S.; Passos, T.M.; Quilty, B.; Thiré, R.M.S.M.; McGuinness, G.B. FTIR analysis and quantification of phenols and flavonoids of five commercially available plants extracts used in wound healing. Rev. Mater. 2016, 21, 767-779. [CrossRef]

21. Anjos, O.; Campos, M.G.; Ruiz, P.C.; Antunes, P. Application of FTIR-ATR spectroscopy to the quantification of sugar in honey. Food Chem. 2015, 169, 218-223. [CrossRef] [PubMed]

22. Estevinho, L.; Pereira, A.P.; Moreira, L.; Dias, L.G.; Pereira, E. Antioxidant and antimicrobial effects of phenolic compounds extracts of Northeast Portugal honey. Food Chem. Toxicol. 2008, 46, 3774-3779. [CrossRef] [PubMed] 
23. Lachman, J.; Orsák, M.; Hejtmánková, A.; Kovářová, E. Evaluation of antioxidant activity and total phenolics of selected Czech honeys. LWT Food Sci. Technol. 2010, 43, 52-58. [CrossRef]

24. Kassim, M.; Achoui, M.; Mustafa, M.R.; Mohd, M.A.; Yusoff, K.M. Ellagic acid, phenolic acids, and flavonoids in Malaysian honey extracts demonstrate in vitro anti-inflammatory activity. Nutr. Res. 2010, 30, 650-659. [CrossRef] [PubMed]

25. Luís, Â.; Domingues, F.; Gil, C.; Duarte, A.P. Antioxidant activity of extracts of Portuguese shrubs: Pterospartum tridentatum, Cytisus scoparius and Erica spp. J. Med. Plants Res. 2009, 3, 886-893.

26. Erejuwa, O.O.; Sulaiman, S.A.; Wahab, M.S. Effects of honey and its mechanisms of action on the development and progression of cancer. Molecules 2014, 19, 2497-2522. [CrossRef]

27. Watanabe, M.A.E.; Amarante, M.K.; Conti, B.J.; Sforcin, J.M. Cytotoxic constituents of propolis inducing anticancer effects: A review. J. Pahrmacy Pharmacol. 2011, 63, 1378-1386. [CrossRef]

28. Martinotti, S.; Pellavio, G.; Laforenza, U.; Ranzato, E. Propolis induces AQP3 expression: A possible way of action in wound healing. Molecules 2019, 24, 1544. [CrossRef]

(C) 2020 by the authors. Licensee MDPI, Basel, Switzerland. This article is an open access article distributed under the terms and conditions of the Creative Commons Attribution (CC BY) license (http://creativecommons.org/licenses/by/4.0/). 